\title{
Synthesis and characterization of silver vanadates thin films for photocatalytic applications
}

\author{
F. Gonzalez-Zavala ${ }^{\mathrm{a}, \mathrm{b}, \mathrm{c}, \text { *, L. Escobar-Alarcón }{ }^{\mathrm{a}} \text {, D.A. Solís-Casados }}{ }^{\mathrm{b}}$, M. Espinosa-Pesqueirad ${ }^{\mathrm{d}}$, \\ E. Haro-Poniatowskie, E. Rodríguez-Castellón ${ }^{\mathrm{f}}$, E. Rodríguez-Aguado ${ }^{\mathrm{f}}$ \\ a Departamento de Física, Instituto Nacional de Investigaciones Nucleares, Apdo. Postal 18-1027, Cd. México 11801, Mexico \\ ${ }^{\mathrm{b}}$ Centro Conjunto de Investigación en Química Sustentable UAEM-UNAM, Toluca, Estado de México 50200, Mexico \\ ${ }^{\text {c }}$ Programa de Posgrado en Ciencia de Materiales, Universidad Autónoma del Estado de México, Toluca, Estado de México 50000, Mexico \\ d Departamento de Tecnología de Materiales, Instituto Nacional de Investigaciones Nucleares, Apdo. Postal 18-1027, Cd. México 11801, Mexico \\ e Departamento de Física, Universidad Autónoma Metropolitana Iztapalapa, Apdo. Postal 55-534, Cd. México, Mexico \\ ${ }^{\mathrm{f}}$ Departamento de Química Inorgánica, Facultad de Ciencias, Universidad de Málaga, 29010 Málaga, Spain
}

\section{A R T I C L E I N F O}

Keywords:

Silver vanadates

Thin films

Laser ablation

Thermal evaporation

Photocatalysis

\begin{abstract}
A B S T R A C T
Silver vanadates thin films were deposited by a hybrid deposition system combining laser ablation and thermal evaporation. A high purity vanadium target was ablated using the third harmonic of a Nd:YAG laser whereas high purity silver pellets were evaporated. The as-deposited thin films were subjected to thermal treatments at $400{ }^{\circ} \mathrm{C}$ to obtain crystalline films. For films without $\mathrm{Ag}$ amorphous $\mathrm{V}_{2} \mathrm{O}_{5}$ thin films were deposited and as the $\mathrm{Ag}$ is incorporated in the material different silver vanadates were obtained. The effect of the silver load on the composition, structure, optical properties, surface morphology and photocatalytic response of the deposited films was studied. The film composition, determined by X-ray photoelectron spectroscopy, reveals Ag contents from 5.5 to 18.9 at.\%. The crystalline phases formed were identified by micro-Raman Spectroscopy; the results indicate the formation of three silver vanadates depending on the silver content. The morphology was observed using scanning electron microscopy, the films surface changes from a smooth surface to belts covering the surface and finally Ag nanoparticles are observed at the higher Ag contens. Optical properties determined from UV-vis reveal the presence of the surface plasmon signal in films containing silver. The films were tested in the photocatalytic degradation of Malachite Green dye reaching maximum degradations degrees close to 53\% under solar irradiation. Reactive species trapping experiments suggest that $\mathrm{O}_{2}{ }^{-\bullet}$ produced by the $\mathrm{O}_{2}$ reduction via the photogenerated electrons drives the photodegradation mechanism.
\end{abstract}

\section{Introduction}

Wastewater treatment using photocatalysis has been widely investigated in the last years due to the advantages offered by the so-called Advanced Oxidation Processes. Although several semiconductors as $\mathrm{TiO}_{2}$, $\mathrm{ZnO}, \mathrm{V}_{2} \mathrm{O}_{5}, \mathrm{Fe}_{2} \mathrm{O}_{3}$ and $\mathrm{SnO}_{2}[1]$ have been studied as photocatalyst materials, most of them requires UV excitation; therefore, improvement of the photocatalytic performance under visible irradiation using solar light is a key issue.

In the last decades silver vanadium oxides (SVO) have received much attention due to their great diverse variety of crystalline struc- tures endowing them with unique physical and chemical properties. SVOs have been used in electronic devices such as electrochromic coatings, gas sensors, cathodes for intercalation lithium batteries, as antibacterial coatings $[2,3]$ and in the photocatalytic degradation of organic compounds dissolved in wastewaters such as crystal violet (CV) [4], methylene blue (MB) [5] and rhodamine $\mathrm{B}(\mathrm{RhB})[6,7]$ as an alternative to conventional catalysts as $\mathrm{TiO}_{2}$ [8]. The development of photocatalysts in thin film form has been explored in the last years due to the advantages of this kind of nanomaterials compared with their counterparts in powder form, a recovery procedure is not required and a very lower amount of material produces the same result. Thin films of

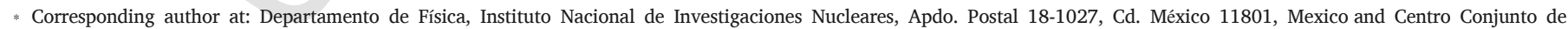
Investigación en Química Sustentable UAEM-UNAM, Toluca, Estado de México 50200, Mexico

Email address: ferngoz@hotmail.com (F. Gonzalez-Zavala) 
SVO have been prepared by various methods on different substrates, the techniques employed include: magnetron sputtering [9], aerosol assisted chemical vapor deposition [10], sol gel [11] and pulsed laser deposition (PLD) [12], among others. On the other side, a lot of work has been dedicated in the last years to investigate deposition techniques to prepare oxide thin films modified with metals trying to have good control of the metal amount that allows metal doping as well as to produce the metal oxide to have mixtures of oxides. The laser ablation technique for thin film deposition allows the possibility of applying different variants to prepare materials with novel properties. In particular, the implementation of a hybrid deposition configuration has been successfully used to prepare vanadium oxide thin films modified with $\mathrm{Ag}$ with good control of the composition [13]. It must be emphasized that preparation of silver vanadates in thin film form remains as a challenge; thin films of $\mathrm{Ag}_{3} \mathrm{VO}_{4}$ are difficult to prepare by common deposition techniques, attempts to stabilize the $\beta-\mathrm{Ag}_{3} \mathrm{VO}_{4}$ phase in thin film form have been unsuccessful by both sputtering and pulsed laser deposition [14]. One of the aims of this work is to address some of these difficulties by depositing thin films of silver vanadates by means of a hybrid deposition configuration combining two physical deposition techniques, laser ablation and thermal evaporation, in this way SVOs with different silver contents are obtained.

\section{Experimental}

The deposition process of silver vanadates thin films was carried out inside a vacuum chamber at a working pressure of $2 \times 10^{-6}$ Torr. A vanadium target was ablated using the third harmonic of a Nd:YAG laser ( $355 \mathrm{~nm}$ ) with a pulse duration of $5 \mathrm{~ns}$ and a repetition rate of $10 \mathrm{~Hz}$; the pulse energy was kept at $8 \mathrm{~mJ}$ for all experiments resulting in laser fluences close to $5 \mathrm{~J} / \mathrm{cm}^{2}$. All deposits were performed with the substrate at room temperature. The amount of silver incorporated in the thin films was varied by changing the $\mathrm{Ag}$ deposition rate from $0.05 \AA \mathrm{A} / \mathrm{s}$ for the sample with the lowest silver content up to $0.5 \AA$ /s for the sample with the higher silver content; the silver deposition rate was monitored by a quartz microbalance placed parallel to the substrate measuring the deposited silver thickness. Subsequently the obtained films were thermally treated at $400{ }^{\circ} \mathrm{C}$ for $2 \mathrm{~h}$ in a convection oven open to the environment in order to oxidize the remaining metallic vanadium and to increase the crystalline quality of the films. The analysis of the chemical composition was performed by X-ray photoelectron spectroscopy (XPS). The XPS measurements were carried out using a PHI Mod. 5700 system equipped with a $\mathrm{Mg}$ X-ray source $(\mathrm{h} \nu=1253.6 \mathrm{eV})$. The high-resolution spectra were acquired with a pass energy of $29.3 \mathrm{eV}$. The spectra treatment was performed with the Multipak Software. The crystalline microstructure was characterized by Raman spectroscopy (RS) using an HR LabRam 800 system with an Olympus BX40 confocal microscope; a $\mathrm{Nd}$ :YAG laser beam $(532 \mathrm{~nm})$ was focused with a $100 \mathrm{X}$ objective onto the sample surface. Surface morphology was observed by scanning electron microscopy (SEM) using a JEOL JSM 6510LV microscope. Optical properties were determined from UV-vis measurements performed with a Perkin Elmer lambda 35 spectrometer.

The photocatalytic activity was tested in the degradation of the Malachite green (MG) dye in an aqueous solution $(10 \mu \mathrm{mol} / \mathrm{L})$ activating the photocatalysts with a solar simulator at power densities close to $30 \mathrm{~mW} / \mathrm{cm}^{2}$. The reaction system was prepared by introducing the thin film into a $25 \mathrm{~mL}$ of the MG solution, afterwards, the reaction system was stirred in dark condition to establish adsorption equilibrium between dye solution with the photocatalyst. This was done as the first step in the photodegradation measurements; in general terms, approximately $13-17 \%$ of MG dye was removed by adsorption from the test solution within the first $10 \mathrm{~min}$ with each photocatalyst in the dark condition, reaching the equilibrium in approximately $10 \mathrm{~min}$. The degradation measurements were performed starting at this time.

In order to gain insight about the photodegradation mechanism, reactive species trapping experiments were performed. Triethanolamine (TEOA, $0.01 \mathrm{M}$ ), $p$-benzoquinone (BZQ, $0.001 \mathrm{M}$ ) and isopropanol (IPA, $0.02 \mathrm{M})$ were employed as scavengers for photogenerated holes $\left(\mathrm{h}^{+}\right)$, superoxide anion radicals $\left(\mathrm{O}_{2}{ }^{-} \bullet\right)$ and hydroxyl radicals $\left({ }^{\bullet} \mathrm{OH}\right)$ [15], respectively. The scavengers were added into the photocatalytic reaction system containing $10 \mu \mathrm{mol} / \mathrm{L}$ solution of MG dye. The MG degradation was followed by the intensity decrease of its characteristic absorption band at $619 \mathrm{~nm}$. The absorbance values were correlated to MG concentrations through a calibration curve. Kinetic reaction constants $\left(\mathrm{k}_{\mathrm{app}}\right)$ were calculated assuming a pseudo-first order reaction from the Ln C versus time graphs

\section{Results and discussion}

\subsection{Compositional analysis}

X-ray photoelectron spectroscopy (XPS) results showed that thin films are composed of vanadium, oxygen and silver with a small amount of adventitious carbon. The atomic contents of silver were varied from 5.5 at.\% for the thin film with the lowest silver thickness up to 18.9 at.\% for the film with the higher silver thickness as is showed in Fig. 1. The monotonic behavior of the data indicates that the total $\mathrm{Ag}$ thickness is a good parameter to control the amount of silver incorporated in the film.

The high resolution XPS spectra of the Ag- $3 d$ region are shown in Fig. 2a. The sample with the lowest silver content present two asymmetric peaks centered at 367.3 and $373.3 \mathrm{eV}$ corresponding to the $\mathrm{Ag}-3 d_{5 / 2}$ and $\mathrm{Ag}-3 d_{3 / 2}$ levels characteristics of $\mathrm{Ag}^{+}$[16]. It is clearly observed a shift of these peaks to higher binding energies, indicating a change to a lower oxidation state. Samples with silver contents greater than 7.9 and up to 8.3 at.\%, show peaks centered at 368.4 and 374.4 corresponding to an $\mathrm{Ag}^{0}$ and $\mathrm{Ag}^{+}$oxidation states attributed to a mixture of metallic silver and silver vanadates, $\mathrm{AgVO}_{3}$ and $\mathrm{Ag}_{3} \mathrm{VO}_{4}$ [17].

The Ag-MNN signal was analyzed to discern metallic silver and silver oxide since this signal is very sensitive to changes in the oxidation states of silver. Fig. $2 \mathrm{~b}$ shows the AES spectra of the different samples. Two main signals around 351 and $356 \mathrm{eV}$, corresponding to the $\mathrm{M}_{4} \mathrm{~N}_{45} \mathrm{~N}_{45}$ and $\mathrm{M}_{5} \mathrm{~N}_{45} \mathrm{~N}_{45}$ Auger transitions are observed [18]. The Auger spectra of samples with $\mathrm{Ag}$ contents greater than 9.4 at.\% show the presence of a shoulder at higher energies increasing its intensity as the Ag content increases. These results suggest that at lower Ag contents the material is formed by a silver oxide that starts to reduce to

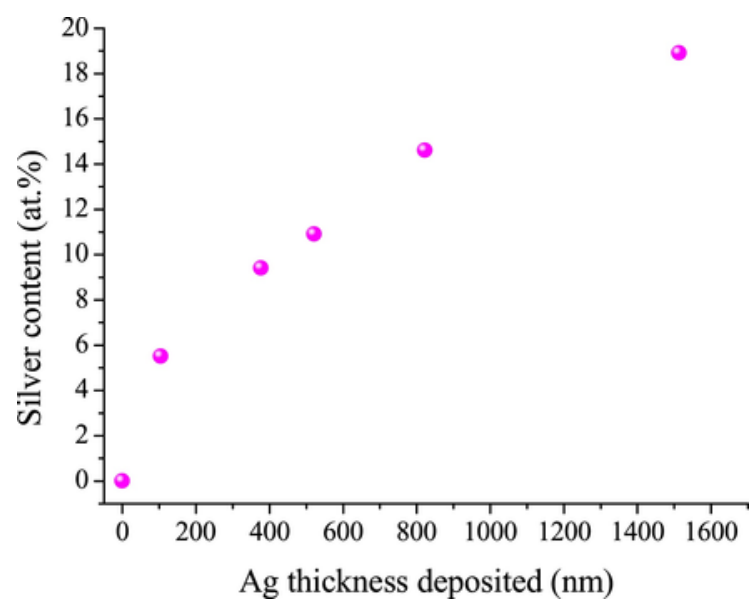

Fig. 1. Silver content in the films as a function of the total Ag thickness. 


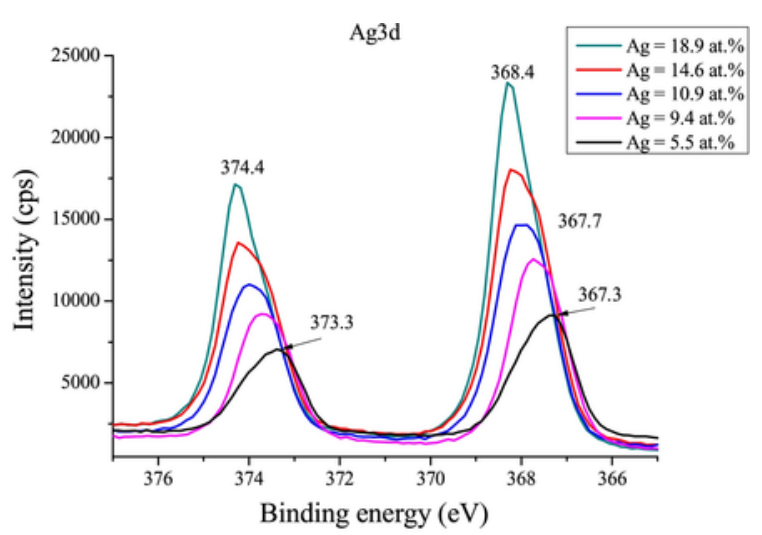

a)

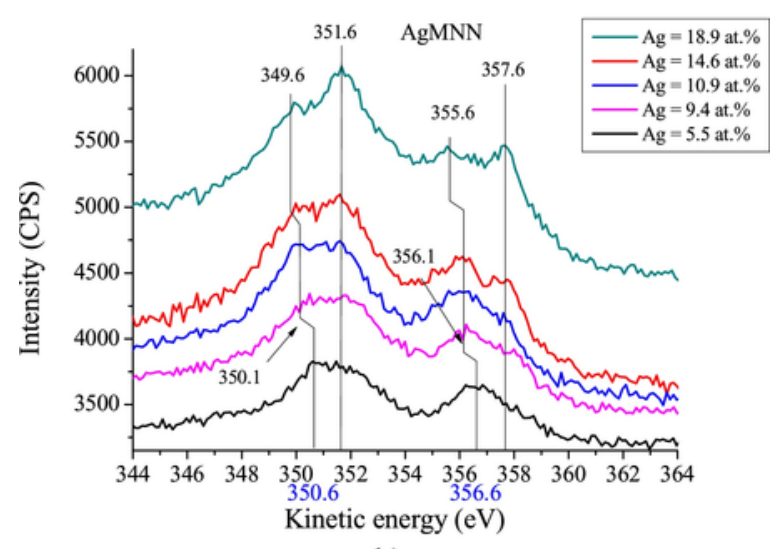

b)

Fig. 2. a) high resolution XPS spectra of the $\mathrm{Ag}$ - $3 d$ region of samples with different $\mathrm{Ag}$ content; b) AES spectra of the Ag-MNN signal of the different samples.

metallic silver as the silver content increases. Therefore, the Auger spectra suggest that prepared materials consist of a mixture of oxidized silver with metallic silver, increasing the metallic component as the silver content is increased.

\subsection{Raman spectroscopy}

Fig. 3 shows the Raman spectra of samples with different Ag content. As it can be observed, the Raman spectra show different vibrational features, indicating different structural arrangements depending on the Ag content. The lowest spectrum in Fig. 3, corresponding to the sample without silver, only shows the peaks due to the silicon substrate indicating the amorphous nature of the deposited material. The Raman spectrum of the sample with the lowest Ag content (5.5 at.\%) is characterized by vibrational modes at 730, 808, 845 and $888 \mathrm{~cm}^{-1}$, that agrees well with those reported for the beta phase of $\mathrm{AgVO}_{3}$ [19]. No changes in the Raman spectrum are observed when the $\mathrm{Ag}$ content increases to 9.4 at.\%, only a lowering of the Raman intensity. The Raman spectra were normalized to the intensity of the second order silicon signal (the band is centered about $950 \mathrm{~cm}^{-1}$ ) in order to compare clearly the different features present in the various spectra. This is the reason why the noise to signal ratio is seen higher in the spectra with increasing atomic\% of Ag. Evident modifications are clearly seen in Raman spectra of samples with $\mathrm{Ag}$ contents of 10.9 and 14.6 at.\%, in which a wide band from 750 to $870 \mathrm{~cm}^{-1}$ appears, suggesting structural disorder of the $\mathrm{AgVO}_{3}$ lattice induced by the incorporation of silver. This band can be considered as the convolution of peaks at 790, 809 and $830 \mathrm{~cm}^{-1}$, that could be attributed to the formation of $\mathrm{Ag}_{4} \mathrm{~V}_{2} \mathrm{O}_{7}$ [20] Finally, for the highest silver content (18.9 at.\%) the presence of an intense peak at $788 \mathrm{~cm}^{-1}$, characteristic of $\mathrm{Ag}_{3} \mathrm{VO}_{4}$ as well as less intense signals due to $\mathrm{AgVO}_{3}$ are observed [21] indicating that at this $\mathrm{Ag}$ content, the deposited material is formed by a mixture of silver vanadates, $\mathrm{AgVO}_{3}$ and $\mathrm{Ag}_{3} \mathrm{VO}_{4}$, prevailing the $\mathrm{Ag}_{3} \mathrm{VO}_{4}$ as the main phase. Therefore, the Raman results indicate the formation of silver vanadates following the next phase evolution: $\mathrm{AgVO}_{3} \rightarrow \mathrm{AgVO}_{3}+\mathrm{Ag}_{4} \mathrm{~V}_{2} \mathrm{O}_{7} \rightarrow \mathrm{Ag}_{3} \mathrm{VO}_{4}+\mathrm{AgVO}_{3}$.

\subsection{Optical properties}

The UV-vis spectra corresponding to the different deposited samples are shown in Fig. 4a. For samples containing Ag, the UV-vis spectra clearly show an absorption band around $421 \mathrm{~nm}$ attributed to the surface plasmon of Ag nanoparticles [22]. As the Ag content increases, it is observed that the absorption band increases its intensity indicating

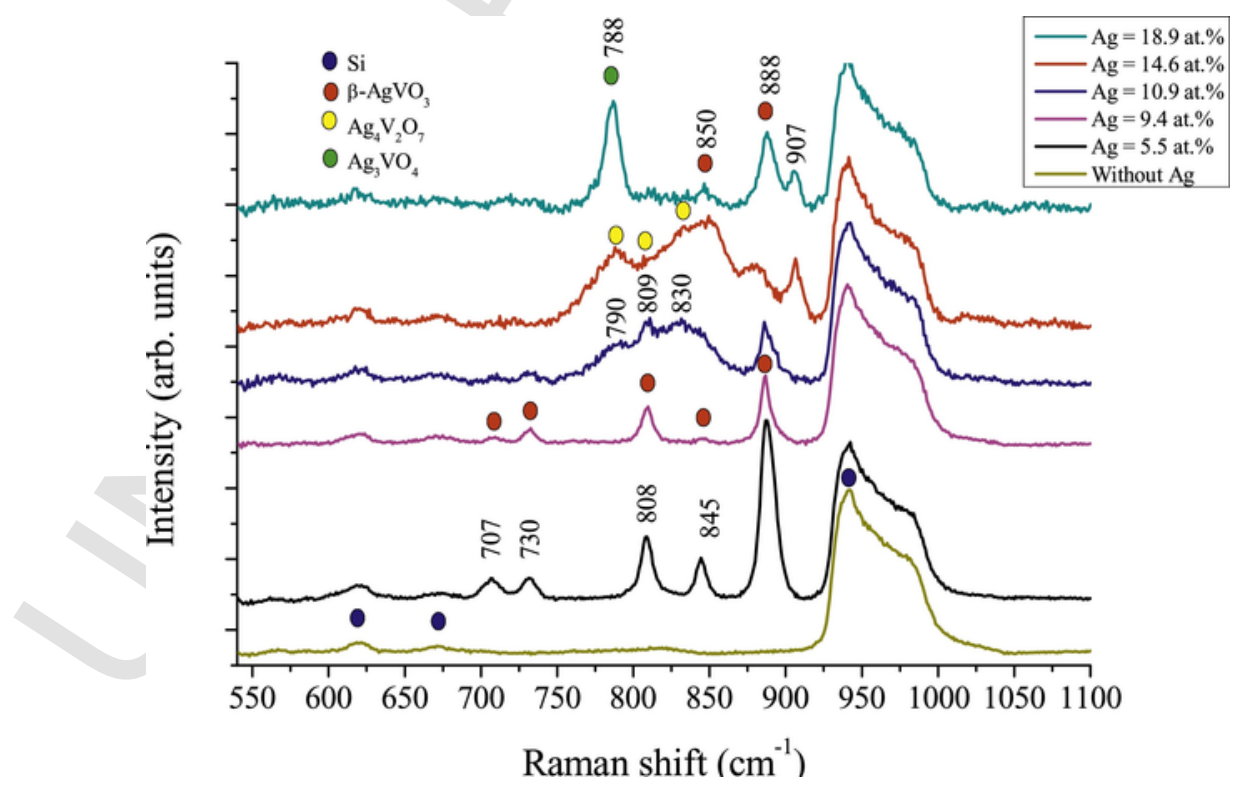

Fig. 3. Raman spectra of samples with different $\mathrm{Ag}$ content. 


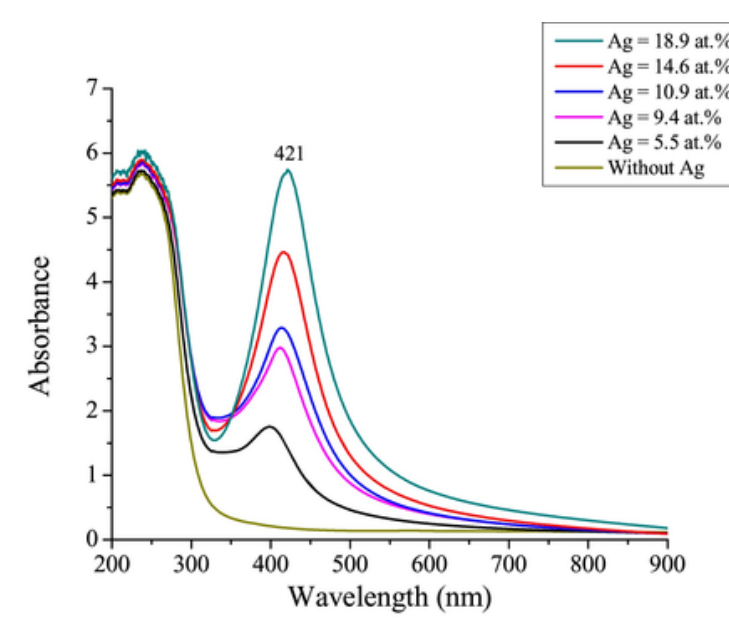

a)

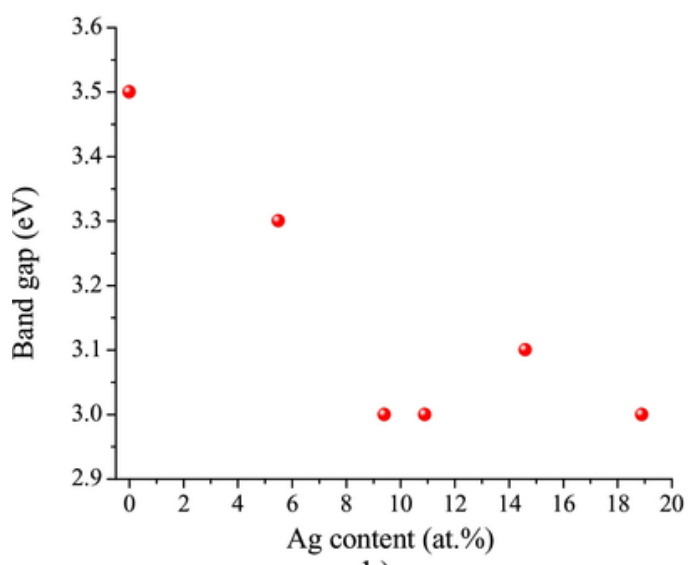

b) contents greater than 9.4 at.\% as is shown in Fig. 4b. These last band gap values are in the visible light region $(413 \mathrm{~nm})$.

\subsection{Surface morphology}

Fig. 5 shows SEM micrographs of the films surface containing different $\mathrm{Ag}$ amounts. The sample without $\mathrm{Ag}$ exhibits a surface without any feature. At the lowest Ag content, a surface covered with nanobelts with some $\mathrm{Ag}$ nanoparticles scattered is observed. Increasing the amount of silver in the film to 9.4 at.\%, increase the number of silver nanoparticles and the nanobelts show clearly the presence of smaller particles on their surface. At a Ag content of 10.9 at.\%, the surface is covered by spherical particles that according to EDS measurements are of silver and the nanobelts are practically disappeared. Further addition of $\mathrm{Ag}$, increases the number of Ag nanoparticles and their size for the highest Ag content. These results suggest that the presence of silver induces the segregation of silver vanadates and at the same time a coalescence process that promotes the formation of silver nanoparticles.

The TEM image of the sample with an $\mathrm{Ag}$ content of 9.4 at.\% shows the presence of silver nanoparticles covering the silver vanadate nanobelt as is observed in Fig. 6a. A closer view of one of these nanobelts reveal nanoparticle sizes of less than $20 \mathrm{~nm}$ (Fig. 6b). This result suggests that nanobelts decorated with $\mathrm{Ag}$ nanoparticles are obtained for silver contents lower than 9.4 at.\%.

\subsection{Photocatalytic activity}

Films with an area of approximately $1 \mathrm{~cm}^{2}$ and photocatalyst mass from 150 to $300 \mu \mathrm{g}$ were used to evaluate the photocatalytic activity. Fig. 7a shows the degradation degree of MG dye as a function of the reaction time using the deposited films with different Ag contents. Degradation degree was determined from the decrease in the characteristic absorption band of the MG at $619 \mathrm{~nm}$ through a concentration calibration curve. It is observed that the sample without silver reaches a maximum conversion degree close to $37 \%$ after $180 \mathrm{~min}$ of reaction time. When a silver amount of 5.5 at.\% is incorporated in the film, a decrease in the degradation degree is observed. The lower degradation degree of the samples containing up to 9.4 at $\%$ of silver can be explained by two reasons: first, these samples exhibit a high recombination rate as PL measurements reveal (figure not included), approximately 8 times greater than the $\mathrm{V}_{2} \mathrm{O}_{5}$ sample, consequently, a lower photocatalytic response is expected; second, it has been reported elsewhere that compared with other Ag-based materials $\mathrm{AgVO}_{3}$ exhibits a

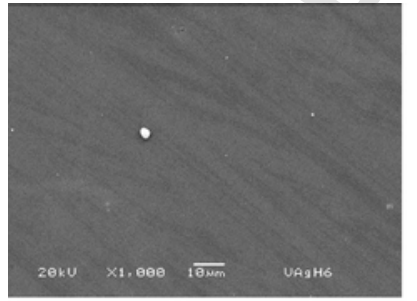

a)

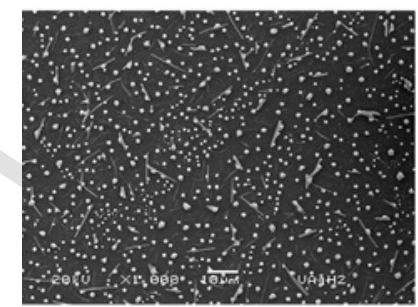

d)

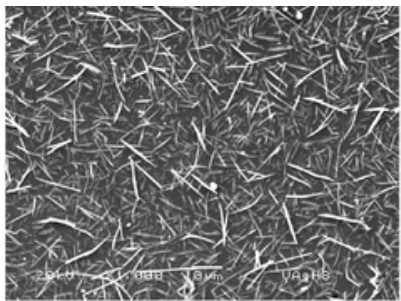

b)

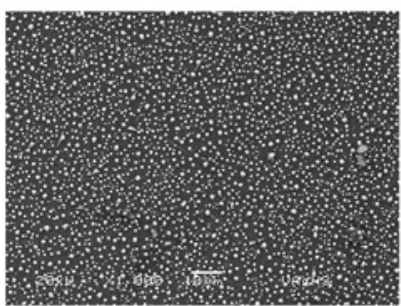

e)

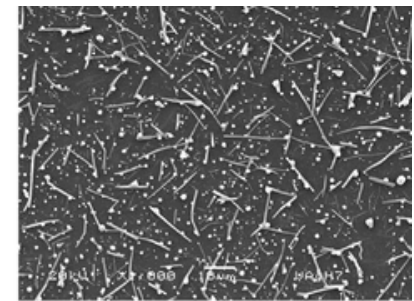

c)

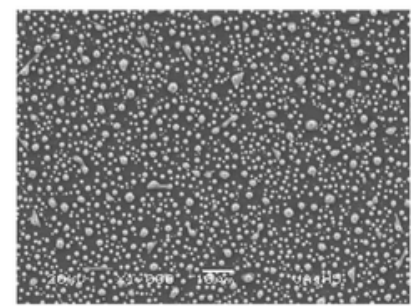

f)

Fig. 5. SEM micrographs of the films surface containing different Ag amounts: a) 0, b) 5.5, c) 9.4, d) 10.9, e) 14.6 and f) 18.9 at.\%. 

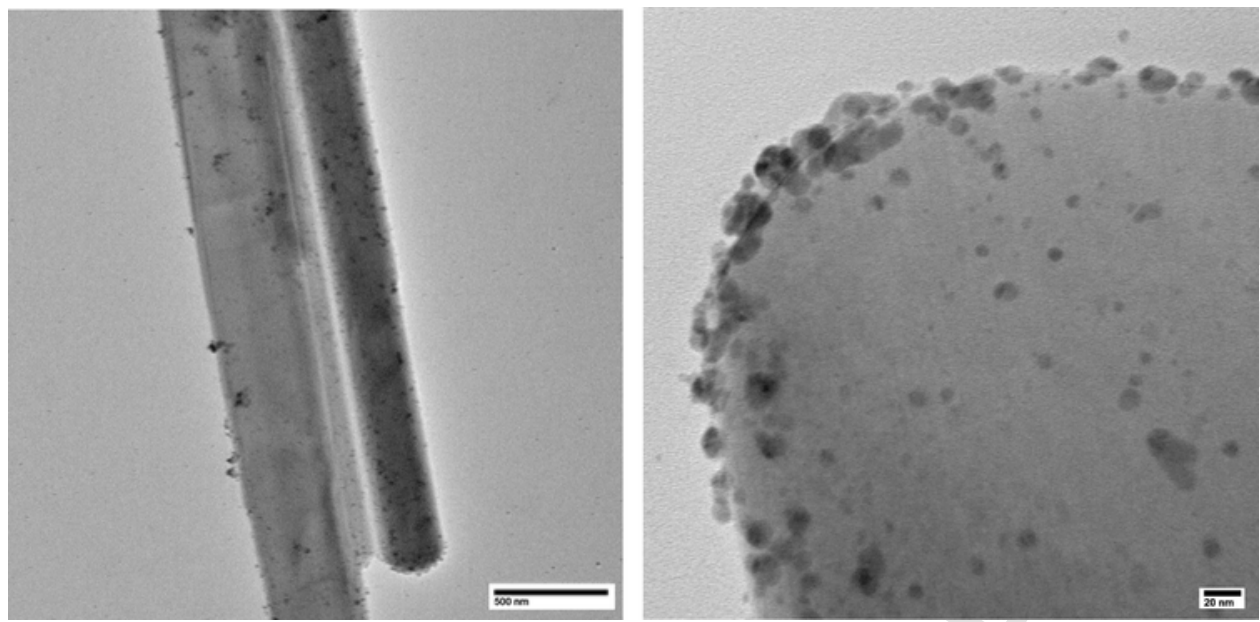

Fig. 6. TEM images of the sample with an Ag content of 9.4 at.\% showing the vanadates nanobelts decorated with silver nanoparticles.

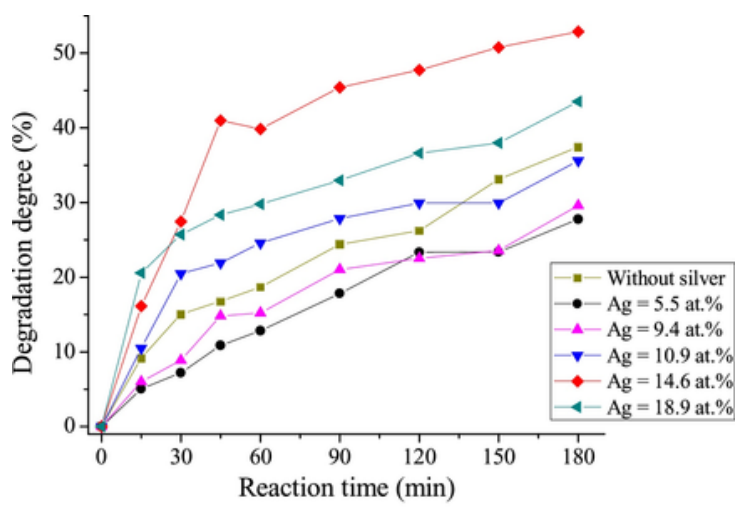

a)

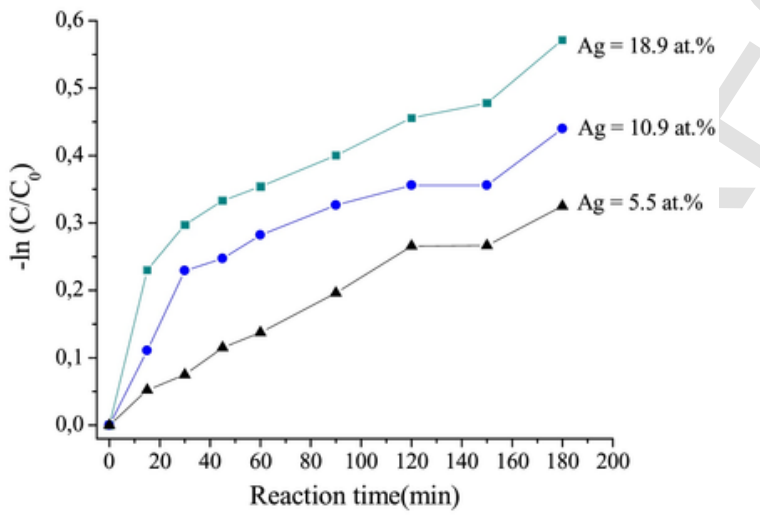

b)

Fig. 7. a) degradation degree of MG dye using the deposited films with different Ag contents; b) graph of $-\ln \left(\mathrm{C} / \mathrm{C}_{0}\right)$ vs reaction time for samples containing $5.5,10.9$ and 18.9 at.\% of Ag.4.

low quantum yield and poor absorption in the visible light region [24]. In order to decrease the electron-hole recombination and increase the charge carrier separation, hybrid materials such as $\mathrm{Ag}_{3} \mathrm{VO}_{4} / \beta-\mathrm{AgVO}_{3}$ have been prepared with higher photocatalytic activity than single $\mathrm{Ag}_{3} \mathrm{VO}_{4}$ and $\beta-\mathrm{AgVO}_{3}$. This also explains the higher degradation degrees obtained with samples with higher silver content [24]. After that, the samples containing silver exhibit an increase in their photocatalytic activity; in fact, films with $\mathrm{Ag}$ contents greater than 10.9 at.\% show better activity than the sample without silver, reaching degradations around 53\% for reaction times of $180 \mathrm{~min}$, almost 50\% the conversion achieved by the photocatalyst without silver. Further addition of Ag to the film decrease the degradation degree, showing a reduction to values close to $43 \%$, even higher than the film without Ag. It is worth mention that even the relative low degradation degrees obtained, the photocatalysts were activated with solar light. The degradation reaction was performed two times for each sample and it was found a maximum reduction of $53 \%$ from the values obtained for the first reaction, indicating poor stability of the tested films. To increase the stability of these films is an important issue to be solved.

Fig. $7 \mathrm{~b}$ shows the graph of $-\ln \left(\mathrm{C} / \mathrm{C}_{0}\right)$ vs reaction time, where $\mathrm{C}$ is the concentration at time $t$ and $\mathrm{C}_{0}$ the initial concentration, for samples containing 5.5, 10.9 and 18.9 at.\% of $\mathrm{Ag}$. It is clearly observed a linear behavior of the data for lower $\mathrm{Ag}$ contents, suggesting a first order kinetic reaction. For Ag loads greater than 10.9 at.\% a no-linear tendency is observed probably due to a higher order reaction or to a combination of different kinetics orders.

The proposed photocatalytic degradation mechanism, based on reviews [25-27] and the results of this work, is as follows: the first step is the absorption of light with energy equal to or greater than the band gap energy of the material; as a result, the photon absorption causes the transfer of electrons from the valence band to the conduction band with the subsequent generation of holes in the valence band. The migration of these charge-carriers, electrons and holes, to the film surface leads to oxidation and reduction reactions producing hydroxyl $\left({ }^{\circ} \mathrm{OH}\right)$ and superoxide radicals $\left(\mathrm{O}_{2}{ }^{-\bullet}\right)$, respectively. To determine the role of these species in the photodegradation mechanisms, reactive species trapping experiments were performed. Triethanolamine (TEOA), $p$-benzoquinone (BZQ) and isopropanol (IPA) were employed as scavengers for photogenerated holes $\left(\mathrm{h}^{+}\right)$, superoxide anion radicals $\left(\mathrm{O}_{2}^{-\bullet}\right)$ and hydroxyl radicals $\left({ }^{\bullet} \mathrm{OH}\right)$, respectively. It is important to point out, that depending on the nature of the photocatalyst material as well as the molecule to be degraded, diverse kind of scavengers have been used reporting different results $[15,25-27]$; in this work, triethanolamine $p$-benzoquinone and isopropanol were chosen as scavengers for holes, superoxide and hydroxyl radicals. Fig. 8 shows the results of photodegradation of samples containing 5.5 and 14.6 at.\% of $\mathrm{Ag}$ and without silver as well using the different scavengers. It is clearly observed that when TEOA is incorporated into the reaction system a higher degradation degree, close to $80 \%$, is reached. The kinetic reaction constants were calculated and values of -0.0129 and $-0.0124 \mathrm{~min}^{-1}$ for the catalyst with 5.5 and 14.6 at.\% of $\mathrm{Ag}$ and $-0.0115 \mathrm{~min}^{-1}$ for the catalyst without silver. These results suggest that holes have little participation in the MG dye degradation. Under the presence of BZQ, the results showed the lowest degradation degrees indicating that $\mathrm{O}_{2}{ }^{-}$ - is the reactive species that drives the photodegradation mechanism 


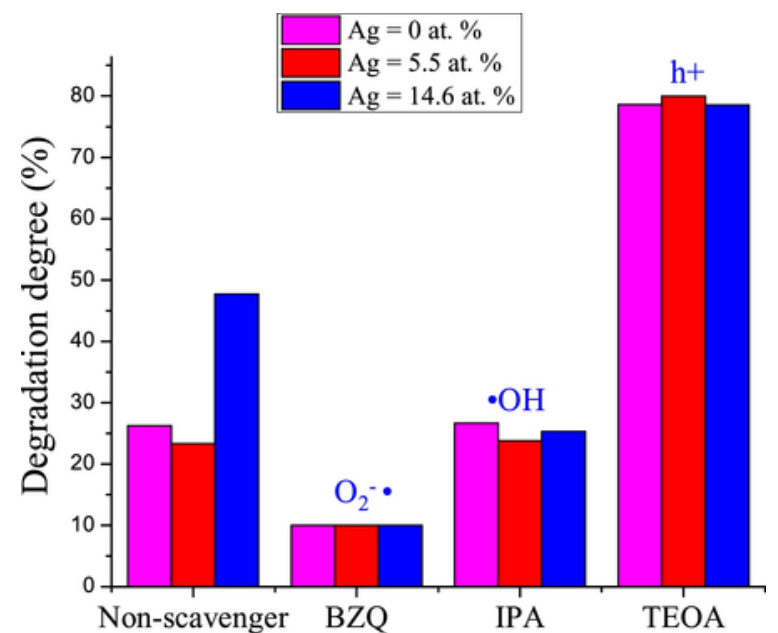

Fig. 8. Photodegradation in presence of different scavengers of samples containing 5.5 and 14.6 at. $\%$ of $\mathrm{Ag}$ and without silver.

through the $\mathrm{O}_{2}$ reduction by the photogenerated electrons; in this case, the kinetic reaction constants were approximately $-0.001 \mathrm{~min}^{-1}$ for all the samples. The use of IPA as scavenger of ${ }^{\bullet} \mathrm{OH}$ radicals, results in degradation degrees close to $25 \%$, assuming that ${ }^{\circ} \mathrm{OH}$ are mainly produced by the $\mathrm{H}_{2} \mathrm{O}$ oxidation by the photogenerated holes, the lower photoactivity compared to the one obtained using TEOA indicates a predominant electron-hole recombination process inhibiting the dye degradation. In this case, the kinetic reaction constants were -0.0057 and $-0.0027 \mathrm{~min}^{-1}$ for the catalysts with 5.5 and 14.6 at.\% of $\mathrm{Ag}$, respectively, and $-0.0027 \mathrm{~min}^{-1}$ for the catalyst without silver. These results suggest a reductive photodegradation mechanism in which the $\mathrm{O}_{2}{ }^{-\bullet}$ reactive species plays a dominant role in the MG mineralization.

\section{Conclusions}

Thin films of different silver vanadates deposited by a hybrid deposition configuration were obtained. It was possible to obtain pure $\mathrm{AgVO}_{3}$ with good crystalline quality at lower $\mathrm{Ag}$ contents and mixtures of $\mathrm{AgVO}_{3}$ and $\mathrm{Ag}_{4} \mathrm{~V}_{2} \mathrm{O}_{7}$ as well as $\mathrm{Ag}_{3} \mathrm{VO}_{4}$ with $\mathrm{AgVO}_{3}$ at higher $\mathrm{Ag}$ contents, being the $\mathrm{Ag}_{3} \mathrm{VO}_{4}$ the main phase; further work is underway to establish suitable conditionts to obtain pure $\mathrm{Ag}_{3} \mathrm{VO}_{4}$. The silver vanadates films with mass as low as $150 \mu \mathrm{g}$ were tested in the photocatalytic degradation of Malachite Green dye reaching maximum degradations degrees close to $53 \%$ under solar irradiation. Reactive specie trapping experiments reveal that $\mathrm{O}_{2}{ }^{-} \bullet$ is the most reactive specie in the MG degradation proccess through the $\mathrm{O}_{2}$ reduction by the photogenerated electrons suggesting a reductive photodegradation mechanism.

\section{Acknowledgements}

This work was partially supported by CONACYT through the projects CB-168827 and the CB-240998. F. Gonzalez-Zavala thanks to
CONACyT for the $\mathrm{PhD}$ and Beca Mixta grants, and also to the SIEA-UAEM for the beca movilidad para estudios avanzados 2016. E. Rodríguez-Castellón thanks to project CTQ2015-68951-C3-3-R of Ministerio de Economía y Competitividad (Spain) and FEDER funds.

\section{References}

[1] J. Anthony Byrne, A. Pilar Fernandez-Ibañez, S.M. Patrick Dunlop, Dheaya, M.A. Alrousan, W.J. Jeremy Hamilton, Int. J. Photoenergy 2011 (2011) 1.

[2] Amin Yoosefi Booshehri, M.I. Polo-Lopez, María Castro-Alférez, Pengfie He, Rong Xu, Wang Rong, Sixto Malato, Pilar Fernández-Ibáñez, Catal. Today 281 (2017) 124.

[3] Cristina Adán, Javier Marugán, Sergio Obregón, Gerardo Colón, Catal. Today 240 (2015) 93.

[4] Zhao Wei, Liang Feng, Jin Zhi-Ming, Shi Xiao-Bo, Yin Peng-Hui, Wang Xue-Ren, Sun Cheng, Gao Zhan-Qi, Liao Liang-Sheng, J. Mater. Chem. A 33 (2) (2014) 13226.

[5] Qing Zhu, Wan-Sheng Wang, Ling Lin, Gui-Qi Gao, Hong-Li Guo, Hong Du, An-Wu Xu, J. Phys. Chem. C 117 (2013) 5894.

[6] Hui Xu, Huaming Li, Li Xu, Chundu Wu, Guangsong Sun, Yuanguo Xu, Jinyu Chu, Ind. Eng. Chem. Res. 48 (2009) 10771.

[7] Puttaswamy Madhusudan, Jingrun Ran, Jun Zhang, Jiaguo Yu, Gang Liu, Appl. Catal. B: Environ. 110 (2011) 286.

[8] Andrew Mills, Stephen Le Hunte, J. Photochem. Photobiol. A 108 (1997) 1.

[9] H.S. Hwang, S.H. Oh, H.S. Kim, W.I. Cho, B.W. Cho, D.Y. Lee, Electrochim. Acta 50 (2004) 485.

[10] D. Vernardou, I. Marathianou, N. Katsarakis, E. Koudoumas, I.I. Kazadojev, S. O'Brien, M.E. Pemble, I.M. Povey, Electrochim. Acta 196 (2016) 294.

[11] L. Znaidi, N. Baffier, M. Huber, Mater. Res. Bull. 24 (1989) 1501.

[12] Yan-Qiu Chu, Qi-Zong Qin, Chem. Mater. 14 (7) (2002) 3152.

[13] F. Gonzalez-Zavala, L. Escobar-Alarcón, D.A. Solís-Casados, C. Rivera-Rodríguez, R. Basurto, E. Haro-Poniatowski, Appl. Phys. A 122 (2016) 461.

[14] V. Cloet, A. Raw, K.R. Poeppelmeier, G. Trimarchi, H. Peng, J. Im, A. Freeman, N. Perry, A. Zakutayev, P. Ndione, D. Ginley, J. Perkins, Chem. Mater. 24 (17) (2012) 3346.

[15] Difa Xua, Bei Cheng, Shaowen Cao, Jiaguo Yu, Appl. Catal. B: Environ. 164 (2015) 380.

[16] M. Bielmann, P. Schwaller, P. Ruffieux, O. Gröning, L. Schlapbach, P. Gröning, Phys. Rev. B 65 (2002), (235431-1).

[17] Tuan A. Vu, Canh D. Dao, Thuy T.T. Hoang, Phuong T. Dang, Hoa T.K. Tran, Kien T. Nguyen, Giang H. Le, Tuyen V. Nguyen, Gun D. Lee, Mater. Lett. 123 (2014) 176.

[18] Ana Maria Ferraria, Ana Patrícia Carapeto, Ana Maria Botelho do Rego, Vacuum 86 (2012) 1998.

[19] Shu-Juan Bao, Qiao-Liang Bao, Chang-Ming Li, Tu Pei Chen, Chang-Qing Sun, Zhi-Li Dong, Ye Gan, Jun Zhang, Small 7 (2007) 1174.

[20] R.C. de Oliveira, L. Gracia, M. Assis, M. Siu Li, J. Andres, E. Longo, L.S. Cavalcante, Cryst. Eng. Comm. 16 (2016) 6483.

[21] S.M. Aouadi, D.P. Singh, D.S. Stone, K. Polychronopoulou, F. Nahif, C. Rebholz, C. Muratore, A.A. Voevodin, Acta Mater. A 58 (2010) 5326

[22] B. Ajitha, Y. Ashok Kumar Reddy, P. Sreedhara Reddy, Powder Technol. 269 (2015) 110.

[23] J. Tauc, R. Grigorovici, A. Vancu, Phys. Stat. Sol. 15 (1966) 627.

[24] Lei Gao, Zhonghua Li, Jiawen Liu, RSC Adv. 7 (2017) 27515.

[25] Chien-Kai Huang, Tsunghsueh Wu, Chang-Wei Huang, Chi-Yung Lai, Mei-Yao Wu, Yang-Wei Lin, Appl. Surf. Sci. 399 (2017) 10.

[26] Lei Xu, Yongge Wei, Wan Guo, Yihang Guo, Yingna Guo, Appl. Surf. Sci. 332 (2015) 682.

[27] Si-Zhan Wu, Kui Li, Wei-De Zhang, Appl. Surf. Sci. 324 (2015) 324. 